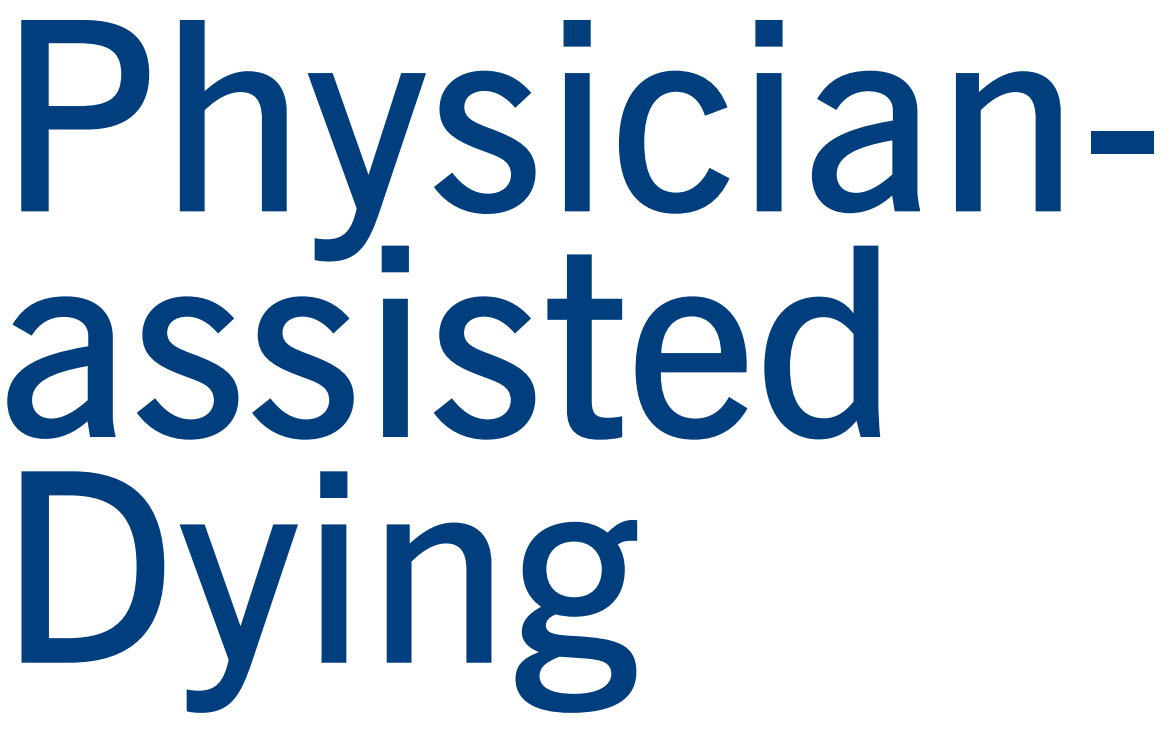

The term physician-assisted dying refers to where, at the request of a mentally competent person, a medical practitioner actively hastens death, by either providing the means by which the patient can take drugs themselves, or directly administering the drugs by injection. An example of prospective legislation for physician-assisted dying in New Zealand, consistent with several other legalised jurisdictions, can be found in Maryan Street's End of Life Choice Bill (2012). Under this bill, individuals may seek medical assistance to die under defined circumstances. He or she (18 years or over) must suffer from either: (a) a terminal illness or other medical condition likely to end his or her life within 12 months (e.g. terminal cancer), or

(b) an irreversible physical or mental condition that, in that individual's view, renders his or her life unbearable (e.g. motor neurone disease).

Safeguards include that the individual must request assistance in writing twice, with a seven-day interval, from a medical practitioner who will certify:

(a) the qualifying condition exists;
Jack Havill is a retired intensive care medicine specialist. He was director of the Waikato Intensive Care Unit for 26 years, dean of the Joint Faculty of Intensive Care Medicine (Australia and New Zealand) 2004-2006, and served briefly as head of the Waikato Clinical School. He is currently president of the Voluntary Euthanasia Society of New Zealand. In 2005 he was made an Officer of the New Zealand Order of Merit for services to medical research and intensive care. (b) there has been no coercion from family or others;

(c) the patient is mentally competent;

(d) advice has been given of treatment options, including palliative care; and

(e) advice is given to talk to family and seek counselling.

In addition, a second medical practitioner must agree with the above. Detailed documentation is sent by the medical practitioners involved to a central registrar who will report to a governmentappointed review committee, who will in turn report to Parliament.

Ethical and related issues

Many issues are raised by opponents of physician-assisted dying, a number of which are addressed here.

\section{Sanctity of life}

In the Western world of medicine, this important concept seems to be derived from: (a) the biblical commandment 'Thou shalt not kill' (from the Ten Commandments); and (b) the classical Hippocratic oath, which says - in this context - 'I will neither give a deadly drug to anybody who asked for it, nor will I make any suggestion to that effect'. More modern oaths usually do not mention the Hippocratic oath (Orr, Pang and Pellegrino, 1997).

The sanctity of life is not absolute. We condone killing someone in certain circumstances: for example, police 
shooting to protect others, and in a just war. There are situations where the action of the medical practitioner will result in an earlier death than otherwise would have occurred, action such as refusal of therapy, withdrawal of therapy, and terminal sedation in palliative care. However, the basic ethical assumption 'in favour of life' is a central tenet of our civilisation. So, what is the issue which really matters here? From time to time the individual will find the release of death to be more important than hanging on to a miserable existence of unbearable suffering, or stretching out the end of a terminal disease. In other words, death which brings an end to suffering is a benefit.

In a strange twist to the arguments for and against physician-assisted dying, the absence of a lawful solution allowing assistance to die may actually shorten life. Sometimes the individual knows that they are weakening as the end approaches, and they commit suicide while they still have the strength to. This was one of the conclusions in a recent Supreme Court of Canada judgment (Supreme Court of Canada, 2015).

\section{The difference between physician-assisted} dying and the withdrawal of life-saving therapy

Medical practitioners have long held the principle that 'passive euthanasia' (withdrawal of support causing death) is very different from active physicianassisted dying. It is claimed that there is a 'bright line' between the two types of actions. In intensive care situations, where life support is being withdrawn because further treatment is considered futile and harmful, the 'bright line' of difference often disappears. The effects can be far more dramatic. Examples include the withdrawal of blood pressure-supporting drugs where life is dependent on them, and the withdrawal of a respirator from a patient dependent on it for life

The Supreme Court of Canada stated in February:

the current unregulated end-of-

life practices in Canada - such as the administration of palliative sedation and the withdrawing or withholding of lifesaving or lifesustaining medical treatment - can have the effect of hastening death and that there is a strong societal consensus that these practices are ethically acceptable. After considering the evidence of physicians and ethicists, [it was] found that the 'preponderance of the evidence from ethicists is that there is no ethical distinction between physicianassisted death and other end-of-life practices whose outcome is highly likely to be death'. (Supreme Court of Canada, 2015) their autonomy, and allows them to say a conscious farewell to their family and friends. However, from a legal point of view, our overly broad, disproportionate criminal law on homicide still regards them as the same. Hence the need for a law change.

The difference between 'suicide' and physician-assisted dying

Irrational suicide is impulsive, often violent, and causes extreme distress to family and friends. Almost always the mental condition which leads to the act is treatable and hence reversible. Physicianassisted suicide is a type of physician-

\section{From an ethical point of view the act of assistance under the carefully prescribed conditions can be considered beneficial to the patient, a compassionate act and respectful of their autonomy ...}

The significance of this is that, even though the New Zealand criminal code supposedly prohibits causing death, this is already accepted medically and legally in certain areas of practice. Furthermore, most of these events occur without the consent of the patient.

\section{The difference between 'killing' and}

\section{physician-assisted dying}

Many opponents of physician-assisted dying seem unable to see the vast ethical difference between murder and physicianassisted dying. When a violent unwanted killing occurs it is called murder and ethical principles are broken through harm being caused to the person, breaching the victim's autonomy, lack of compassion, injustice, and the act being contrary to the law. Physician-assisted dying allows an adult competent person to make a written request to a medical practitioner to assist him or her to die. From an ethical point of view the act of assistance under the carefully prescribed conditions can be considered beneficial to the patient, a compassionate act and respectful of assisted dying where, at the request of the patient, the physician prescribes a drug and the patient takes it to end their life. This is called 'rational suicide' and has the same ethical characteristics as described above. Irrational suicide is completely different from physician-assisted dying, yet again the criminal law on abetting suicide regards them as the same and needs changing.

\section{Autonomy of the patient}

The autonomy of the patient has become an important ethical principle. In New Zealand, under the New Zealand Bill of Rights Act 1990 a patient can refuse any treatment offered even if it is life-saving. Consent must be gained for invasive interventions. An individual can write a legally enforceable Advanced Care document which prescribes how they should be treated should they become incompetent (Code of Health and Disability Services Consumer's Rights, 2009). However, while an individual can live a full, self-determining life making medical decisions, when it comes to dying 
(in New Zealand) they are not allowed to make a decision to determine the manner of their dying, short of committing suicide in isolation.

\section{The 'slippery slope'}

There are two components to this concept:

1. shifting ethical norms: these are always changing in society. For instance, slavery was once accepted. Future generations will have to make these decisions for themselves;

2. that the vulnerable will be at risk of being assisted to die against their will.
Some particular concerns of opponents of physician-assisted dying include:

Depression abuse. The Maryan Street

bill states that the unbearable condition must be 'irreversible'. Most depression is reversible with appropriate care. Rarely, a refractory depression under longterm psychiatric care could possibly be judged to fit the criteria for physician-assisted dying.

Disabled abuse. Patients who are mentally disabled are excluded as a person has to be mentally competent to qualify. If the patient is physically

\section{... palliative care and physician-assisted} dying are not mutually exclusive: the former should be universally provided at a high level, and the latter should be available as an adjunct where requested.

In a study from the Netherlands and Oregon, there is clear evidence that the vulnerable are not at an increased risk in this fashion (Battin et al., 2007). The Canadian Supreme Court, considering the body of evidence from jurisdictions allowing legalised physician-assisted dying, stated that

\section{although none of the systems has achieved perfection, empirical researchers and practitioners who have experience in those systems are of the view that they work well in protecting patients from abuse while allowing competent patients to choose the timing of their deaths.}

The court also stated that 'physicians were capable of reliably assessing patient competence, including in the context of life-and-death decisions. ... $[\mathrm{I}] \mathrm{t}$ was possible to detect coercion, undue influence, and ambivalence as part of this assessment process' (Supreme Court of Canada, 2015). disabled but mentally competent he or she is in no different situation to the non-disabled.

Elderly abuse. The requirements of legislation such the End of Life Choice Bill make abuse of the elderly in the context of physician-assisted dying virtually impossible. The elderly do not qualify for physicianassisted dying by being lonely, depressed, feeling that they are a burden to others or feeling that have completed their life.

Encouraging irrational suicide particularly in the young. There is no evidence to support the contention that physician-assisted dying would encourage suicide. In the Netherlands suicide rates are slightly lower than New Zealand's after 20 years of legalised physician-assisted dying (10/100,000 compared with New Zealand's 10.1/100,000).

Physician-assisted dying impedes the development of palliative care. Experience throughout legalised jurisdictions has confirmed the opposite (Chambaere and Bernheim, 2015).

\section{Palliative and hospice care}

Supporters of physician-assisted dying wholeheartedly endorse these modes of treatment and would see most patients as needing these services. In Oregon, 93\% of patients who have assisted deaths have been treated in a hospice environment (Oregon Public Health Division, 2014). In the Netherlands and Belgium, palliative care doctors have been some of the leaders in the voluntary euthanasia movement (Bernheim et al., 2008)

However, palliative care cannot always relieve physical suffering, or 'existential suffering' due to loss of autonomy and dignity, and there are a number of patients who ask for physician-assisted dying in spite of good palliative care. Also, terminal sedation refers to the situation where a patient is sedated to the point of deep unconsciousness until death. It is used for relief or management of refractory and unendurable symptoms (breathlessness, nausea and vomiting, agitation, fitting, pain and restlessness). Artificial administration of food and fluid is usually withdrawn. The literature describes percentages of deaths being by terminal sedation varying up to $12 \%$ (Onwuteaka-Philepsen et al., 2012). Staff give drugs to relieve suffering and any 'double effect' which may hasten death is regarded as non-intentional. However, it is clear that the patient will die shortly, and where the double effect occurs there is no ethical difference from physicianassisted dying, which is also given to relieve suffering.

Finally, palliative care and physicianassisted dying are not mutually exclusive: the former should be universally provided at a high level, and the latter should be available as an adjunct where requested.

\section{Relationship between doctor and patient}

A frequently used argument against voluntary euthanasia is that the physicianpatient relationship will be destroyed. The evidence from legalised jurisdictions is against this. Indeed, probably the opposite is true. The physician-patient relationship may be enhanced by the patient knowing 
that the physician will not abandon him or her at this particularly moving and intense period of life (an ethical principle of 'non-abandonment'). In 2008 a market research organisation reported that $88 \%$ of respondents in Belgium and 91\% in the Netherlands trust their doctors, one of the highest rankings in Europe (Gfk, 2008)

\section{Human rights}

Closely linked to ethics is a consideration of human rights. The February 2015 Canadian Supreme Court judgment is groundbreaking in this respect. It stated that sections of Canada's criminal code unjustifiably infringe its Charter of Rights and Freedoms: and are of no force or effect to the extent that it prohibits physicianassisted death for a competent adult person who (1) clearly consents to the termination of life and (2) has a grievous and irremediable medical condition (including an illness, disease or disability) that causes enduring suffering that is intolerable to the individual in the circumstances of his or her condition. (Supreme Court of Canada, 2015)

It argued that life, liberty, security and equality are all impeded by a ban on physician-assisted dying, which is fundamentally unjust.

\section{Conclusion}

In summary, the case for legalisation of physician-assisted dying in New Zealand is compelling, and the concerns promulgated by opponents are usually spurious and unsupported by reliable evidence. The opposing ethical stances on physician-assisted dying held by the New Zealand Medical Association and palliative care organisations in New Zealand are no longer valid.

\section{References}

Battin M.P., A. van der Heide, L. Ganzini et al. (2007) 'Legal physicianassisted dying in Oregon and the Netherlands: evidence concerning the impact on patients in "vulnerable" groups', Journal of Medical Ethics, 33 (10), pp.591-7

Bernheim, J., R. Deschepper, W. Diselmans, A. Mullie, J. Bilsen and J. Deliens (2008) 'Development of palliative care and legalization of euthanasia: antagonism or synergy?', British Medical Journal, 336, pp.864-7

Chambaere, K. and J. Bernheim (2015) 'Does legal physician-assisted dying impede development of palliative care?', Journal of Medical

Ethics, February, doi:10.1136/medethics-2014-102116

Gfk (2008) Gfk Trust Index, Gfk Custom Research, 8 August Health and Disability Commissioner (2009) Code of Health and Disability

Services Consumers' Rights, Auckland: New Zealand Government

Oregon Public Health Division (2014) Oregon's Death with Dignity Act 2014, http://www.healthoregon.org/dwd

Orr, R., N. Pang, E. Pellegrino et al. (1997) 'Use of the Hippocratic Oath: a review of the twentieth-century practice and a content analysis of oaths administered at medical schools in the USA and Canada in 1993', Journal of Clinical Ethics, 8 (4), pp.377-88

Onwuteaka-Philepsen, B.D., A. Brinkman-Stoppelenburg, C. Penning et al. (2012) 'Trends in end-of-life practices before and after the enactment of the euthanasia law in the Netherlands from 1990 to 2010: a repeated cross-sectional survey', Lancet, July, http://dx.doi. org/10.1016/S0140-6736(12)61034-4

Supreme Court of Canada (2015) Carter v Canada (Attorney General), [2015] 1 SCR 331, 6 February

\section{Victoria Professional and Executive Development}

High quality professional and executive development courses specifically designed for the public sector:

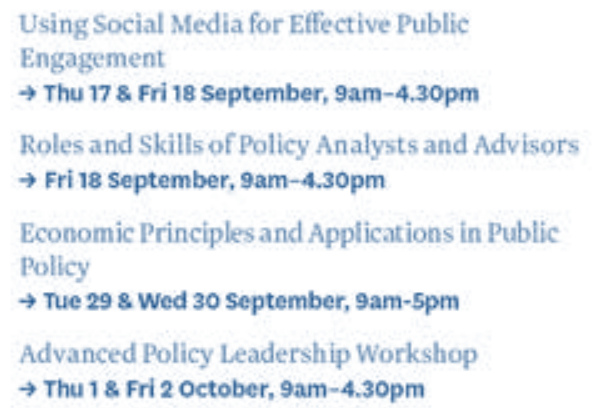

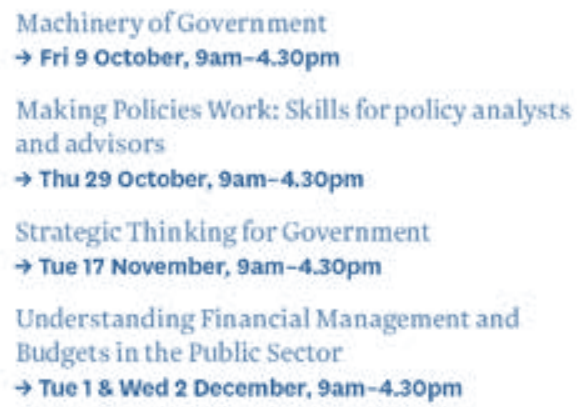

Wealso deliver in-house courses, can customise existing courses or design new programmes to suityour requirements. We can also run courses in Auckland.

For more course dates, further information and to enrol visit www.victoria.ac.nz/profdev or call us on 04-4636556. 